\title{
Cocaine- and Amphetamine-Regulated Transcript Peptide Plays a Role in the Manifestation of Depression: Social Isolation and Olfactory Bulbectomy Models Reveal Unifying Principles
}

\author{
Manoj P Dandekar', Praful S Singru², Dadasaheb M Kokare' and Nishikant K Subhedar*,3 \\ 'Department of Pharmaceutical Sciences, Rashtrasant Tukadoji Maharaj Nagpur University Campus, Nagpur, India; '2Division of Endocrinology, \\ Diabetes and Metabolism, Tufts-Medical Center, Boston, MA, USA; ${ }^{3}$ Indian Institute of Science Education and Research, Pune, Maharashtra, \\ India
}

We investigated the effect of cocaine- and amphetamine-regulated transcript (CART) peptide on depression-like behavior in socially isolated and olfactory bulbectomized (OBX) rats. Administration of CART (54-102) into the lateral ventricle (50-100 ng) or central nucleus of amygdala (CeA) ( $10-20 \mathrm{ng}$ ) caused significant decrease in immobility time in the forced swim test (FST) without influencing locomotion, suggesting antidepressant-like effect. Social isolation as well as OBX models were undertaken to produce depression-like conditions. Although isolation reared (6 weeks) rats showed significant increase in immobility time in FST, OBX animals exhibited hyperactivity (increase in the ambulation, rearing, grooming, and defecation scores) on day 14 in the open-field test. The isolation- or OBX-induced depression-like phenotypes were reversed following acute or subchronic treatment of CART, respectively, given via intracerebroventricular and intra-CeA routes. Drastic reduction in CART-immunoreactivity was observed in most cells in the paraventricular (PVN), arcuate and Edinger-Westphal nuclei of the socially isolated and OBX animals. Although the fibers in the PVN showed variable response, those in ARC and prefrontal cortex did not change. The CART-immunoreactive fibers in the locus coeruleus also showed highly significant reduction. However, dramatic increase in CART-immunoreactive fibers was noticed in the CeA in both the experimental models. The response by the cells and fibers in the periventricular area and perifornical nucleus in the OBX and socially isolated rats was variable. The study underscores the possibility that endogenous CART system might play a major role in mediating symptoms of depression.

Neuropsychopharmacology (2009) 34, 1288-1300; doi:I0.1038/npp.2008.20I; published online I2 November 2008

Keywords: CART; depression; social isolation; olfactory bulbectomy; Porsolt's forced swim test; immunocytochemistry

\section{INTRODUCTION}

Cocaine- and amphetamine-regulated transcript (CART) is a newly discovered peptide (Douglass et al, 1995) that is strongly expressed in the hypothalamus and major limbic structures (Couceyro et al, 1997; Koylu et al, 1997, 1998), is important in feeding behavior, energy expenditure, reproduction, psychomotor activity, and neuroendocrine regulation (Kristensen et al, 1998; Thim et al, 1998; Kimmel et al, 2000; Kuriyama et al, 2004; Smith et al, 2004).

\footnotetext{
* Correspondence: Professor NK Subhedar, Indian Institute of Science Education and Research, First floor, Central Tower, Sai Trinity Building, Garware Circle, Sutarwadi, Pashan, Pune, Maharashtra 4II 02I, India, Tel: +9l 20 25908055, Fax: +91 2025899790 ,

E-mail: nksubhedar@hotmail.com

Received II June 2008; revised 9 October 2008; accepted 9 October 2008
}

Recent evidences demonstrate that CART is crucial in the regulation of the behavioral and physiological responses to stress (Kuhar and Dall Vechia, 1999; Balkan et al, 2003, 2006; Dominguez et al, 2004; Vicentic et al, 2004; Koylu et al, 2006). CART may modulate affective and anxiety behaviors (Stanek, 2006) and exert an augmenting effect in the treatment of depression because it acts as a putative and potential neurotransmitter/cotransmitter that is also involved in psychostimulant action (Jaworski et al, 2003; Jones and Kuhar, 2006). Preliminary results suggest that, CART directly controls the expression of several important neurotransmitters, which are instrumental in processing neuropsychological behaviors (Vaarmann and Kask, 2001; Yang et al, 2004; Jaworski et al, 2007). Ma et al (2007) have suggested that an increase in 5-hydroxytryptamine (5-HT) may contribute to the antidepressant-like effect of CART. Moreover, therapeutic efficacy of CART has been suggested in the treatment of depression and neurodegenerative 
disorders (Lakatos et al, 2005; Wu et al, 2006; Pae et al, 2007; Orsetti et al, 2008).

This study has been undertaken with a view to finding out if CART has a role in mediating depression-related information. We administered CART via the intracerebroventricular (icv) route and also directly into the central nucleus of amygdala (CeA), the site for processing depression-related information (Aggleton, 1993; Hwang et al, 2005; Dannlowski et al, 2008), in normal rats. The response in terms of immobility time was evaluated employing Porsolt's forced swim test (FST) (Porsolt et al, 1978). Social isolation and olfactory bulbectomy (OBX) are widely employed models of depression. Rats were socially isolated for 6 weeks and the depression was evaluated by FST method (Karim and Arslan, 2000; Shabanov and Roik, 2005). Surgical removal of the olfactory bulbs was also undertaken to generate depression and the resulting hyperactivity (increase in the ambulation, rearing, grooming, and defecation scores) was evaluated using open-field test (OFT) (Song et al, 1996; Kelly et al, 1997; Song and Leonard, 2005). CART was also administered by the icv and intra-CeA routes to the OBX and socially isolated (6 weeks) rats, and the responses evaluated in terms of depressive behavior. Moreover, following social isolation and OBX, endogenous CART system was investigated in the paraventricular nucleus (PVN), periventricular area (PeA), arcuate nucleus (ARC), perifornical nucleus (PeF), CeA, prefrontal cortex (PFC), Edinger-Westphal nucleus (EW), and locus coeruleus (LC) using immunocytochemistry coupled with morphometric analysis. These neuroanatomical areas were chosen for this investigation because of abundance of CART (Koylu et al, 1997, 1998; Vrang, 2006), and some of them (PVN, ARC, CeA, PFC, and LC) are reported to be involved in the processing of depressionrelated signals (Baker et al, 1996; Song et al, 1996; Makino et al, 2000; Kim et al, 2003; Stone et al, 2007; Dannlowski et al, 2008; Orsetti et al, 2008). Furthermore, this work provided a unique opportunity to compare the CART immunocytochemical profile in the brain of rats subjected to social isolation and OBX, the two different models for generating depression, and to identify common features, if any.

\section{MATERIALS AND METHODS}

\section{Animals}

Adult male Sprague-Dawley rats (230-250 g) had free access to food (Lipton, India) and drinking water except during the test period. They were maintained on a $12 \mathrm{~h}$ dark/light cycle, in controlled temperature $\left(25 \pm 2{ }^{\circ} \mathrm{C}\right)$ and relative humidity $(50-70 \%)$. The experimental procedures were approved by the Institutional Animal Ethics Committee of Department of Pharmaceutical Sciences, Rashtrasant Tukadoji Maharaj Nagpur University, Nagpur, India.

\section{Intracerebral Cannulations}

The procedures of cannulation and postsurgical care have been described (Kokare et al, 2005, 2006). The cannulae were implanted on the skull of normal, socially isolated (5 weeks) and OBX animals, for the icv or intra-CeA administration of artificial cerebrospinal fluid (aCSF) or CART. A stainless steel guide cannula (C316G/Spc; Plastics One, Roanoke, VA) was implanted into the right lateral cerebral ventricle using the stereotaxic coordinates, $-0.8 \mathrm{~mm}$ posterior, $+1.3 \mathrm{~mm}$ lateral to midline, and $3.5 \mathrm{~mm}$ ventral with respect to bregma (Paxinos and Watson, 1998). Similarly, the cannulae were implanted bilaterally in the CeA with coordinates, $-2.4 \mathrm{~mm}$ posterior, $\pm 4.0 \mathrm{~mm}$ lateral to midline, and $8.0 \mathrm{~mm}$ ventral to bregma in other groups. The animals were allowed a recovery period of 7 days and those with any neurological/motor deficits were excluded from the study.

\section{Intracerebroventricular and Intra-Amygdala Administrations of CART}

The methods of icv and nuclei-specific injections, and preparation of aCSF have already been standardized in our laboratory (Kokare et al, 2005, 2006; Dandekar et al, 2008a). Cannulated rats were randomly allocated to different groups ( $n=9$ in each). All injections were performed between 0900 and 1200 hours and rats, once used, were not reemployed. CART (54-102) was diluted in aCSF and injected into the right lateral ventricle or bilaterally into the CeA. The vehicle (aCSF, $5 \mu \mathrm{l}$ per rat, icv; $n=9$ and $1 \mu \mathrm{l}$ each side, intra-CeA; $n=6)$ or CART (54-102) (25-100 ng per rat, icv; $n=8$ per group and $2-20 \mathrm{ng}$ per rat, intra-CeA; $n=7$ per group) were given as single injection and subjected to the FST or actophotometer following an interval of $30 \mathrm{~min}$.

In the socially isolated animals, vehicle (aCSF, $5 \mu$ l per rat, icv; $n=6$ and $1 \mu$ leach side, intra-CeA; $n=8$ ) or CART (54102) (50-150 ng per rat, icv; $n=7$ per group and 2-20 ng per rat, intra-CeA; $n=9$ per group) were given as single injection, and following an interval of $30 \mathrm{~min}$, the rats were subjected to the FST or actophotometer test. The shamoperated and OBX rats were given daily single injection of the vehicle (aCSF, $5 \mu \mathrm{l}$ per rat, icv; $n=7$ and $1 \mu \mathrm{l}$ each side, intra-CeA; $n=6$ ) or CART (54-102) (25-200 ng per rat, icv; $n=8$ per group and $2-40 \mathrm{ng}$ per rat, intra-CeA; $n=7$ per group) for 7 days, and subjected to the OFT following an interval of $30 \mathrm{~min}$ of last injection. The responses were scored by a trained observer blind to various treatment conditions.

The placement of the cannula for icv injection was tested for accuracy by injecting dilute India ink and postmortem examination of the distribution of ink in the ventricles (Kokare et al, 2006; Dandekar et al, 2008a). Following intraCeA injections, the brains were removed, sectioned, stained with cresyl violet, and the position of the tip of the each injection site was determined. Only animals with correct cannula placements were used for statistical analyses.

\section{OBX and Social Isolation}

Bilateral OBX was performed as described by O'Connor and Leonard (1988). Briefly, rats were anesthetized with thiopental sodium $(40 \mathrm{mg} / \mathrm{kg}$, ip), mounted in a stereotaxic apparatus (David Kopf, USA), and a skin incision was made to expose the skull overlying the bulbs. Holes were drilled $7 \mathrm{~mm}$ anterior to bregma and $2 \mathrm{~mm}$ on either side of the midline at a point corresponding to the posterior margin of the orbit of the eye. The olfactory bulbs were removed by 
suction, the holes were filled with hemostatic sponge in order to control the bleeding and the scalp was sutured. Sham-operated animals received the same surgical treatment, but the bulbs were left intact. The animals were given 14 days to recover following the surgery. No noticeable aggressive behavior was observed in the OBX rats. Thereafter, the rats were (1) subjected to aCSF/CART treatment followed by behavioral analysis using OFT or (2) processed for immunocytochemical labeling.

In the social isolation group, male rats, maintained under a $12 \mathrm{~h} \mathrm{light/dark} \mathrm{cycle} \mathrm{with} \mathrm{food} \mathrm{and} \mathrm{water} \mathrm{ad} \mathrm{libitum,} \mathrm{were}$ either housed in groups of $4-5$ per cage $(24 \times 17 \times 12 \mathrm{~cm})$ or kept individually after weaning (isolated in the cage of similar dimensions) for 6 weeks before conducting the experiments. At the end, paired and socially isolated rats were (1) injected with aCSF/CART and subjected to FST assessment or (2) processed for immunocytochemical labeling.

\section{Porsolt's FST for Depression}

The FST is a behavioral model, which predicts the efficacy of prospective antidepressant-like drugs in rat (Porsolt et al, 1978). The method has already been described (Goyal et al, 2006; Kokare et al, 2008). Briefly, the animals are individually forced to swim in cylindrical glass tank and the behavior is evaluated by quantifying the duration of immobility. Two swimming sessions were carried out with an initial $15 \mathrm{~min}$ 'pretest' followed by $5 \mathrm{~min}$ 'test' after $24 \mathrm{~h}$. Animals (normal and socially isolated) were either treated icv or intra-CeA with aCSF/CART before test session.

\section{Locomotor Activity Measurement}

Locomotor activity was monitored with actophotometer (Centroniks Electronic, India) of $38 \mathrm{~cm}$ diameter and $16 \mathrm{~cm}$ height, equipped with photocells that automatically measure the animal's movement. Spontaneous locomotor activity of each rat was measured for 10 min period. All animals were used only once and after each test the actophotometer grid floor was carefully cleaned.

\section{OFT for Assessing Hyperactivity}

On day 14 following the surgery, and at the end of subchronic treatment with aCSF/CART, OBX, and shamoperated control rats were subjected to the OFT. Each rat was placed at the center of the open-field apparatus designed according to the specifications of Redmond et al (1999) with slight modifications. It consisted of circular arena (diameter $80 \mathrm{~cm}$ ) divided into square areas of $10 \mathrm{~cm}^{2}$ each. The entire arena was provided with a $75 \mathrm{~cm}$ high aluminum walls on the periphery. A $60 \mathrm{~W}$ light bulb was positioned $90 \mathrm{~cm}$ above the center of the arena, and provided the only source of illumination in the testing room. Each animal was placed in the center of the openfield apparatus, and the ambulation (number of crossovers), rearing, grooming, and defecation scores were measured during a 3 min period.

\section{Immunocytochemistry}

Brains of socially isolated and OBX animals, along with their respective controls, were processed for immunocytochemical labeling with CART antibody. Rats were deeply anesthetized (thiopental sodium, $60 \mathrm{mg} / \mathrm{kg}$, ip), perfused transcardially with heparinized phosphate-buffered saline (PBS; pH 7.4) for $30 \mathrm{~s}$ followed by $4 \%$ paraformaldehyde in $0.1 \mathrm{M}$ phosphate buffer ( $\mathrm{pH}$ 7.4) for $10-15 \mathrm{~min}$. The brains were post-fixed in the same fixative overnight, cryoprotected in 30\% sucrose solution in PBS, embedded, and serially sectioned on a cryostat (Leica, Germany) at $20 \mu \mathrm{m}$ thickness in the coronal plane and collected in PBS. Sections were processed for CART-immunolabeling using the streptavidin-biotin-peroxidase method described earlier (Dandekar et al, 2008a,b). Sections were incubated in mouse monoclonal primary antibodies against CART (54102 ) diluted in $1 \%$ bovine serum albumin (BSA; Sigma) containing $0.3 \%$ Triton X-100 and $0.09 \%$ sodium azide at 1:5000 dilution for 2 days at $4^{\circ} \mathrm{C}$. After rinsing in $\mathrm{PBS}$, sections were incubated in biotinylated-IgG followed by $\mathrm{ABC}$ (Vector) and the immunoreaction product was developed in diaminobenzedine $/ \mathrm{H}_{2} \mathrm{O}_{2}$ in Tris buffer. Sections were dehydrated, cleared in xylene, and mounted with DPX. Sections from the brains of different groups were processed at the same time under identical conditions to ensure reliable comparisons among different groups and maintain stringency in tissue preparation and staining conditions. The details of generation of CART antibody and its specificity have been described earlier (Thim et al, 1998). Omission of the primary antibody and replacement with BSA produced no immunoreaction. In preadsorption controls, application of $1 \mathrm{ml}$ diluted antibody pre-incubated with CART at $10^{-5} \mathrm{M}$ for $24 \mathrm{~h}$, completely blocked the immunoreaction.

\section{Morphometric Analysis}

The area occupied by CART-immunoreactive (CART-ir) cells and/or fibers in the PVN, PeA, PFC, ARC, PeF, CeA, $\mathrm{EW}$, and LC was evaluated using microscopic images from predetermined areas in the sections. The images $(\times 480)$ were analyzed using Leitz-LaborLux $S$ microscope, CCD video camera system (JVC, Japan), and Leica-Qwin Standard software. The method has already been standardized in our laboratory (Dandekar et al, 2008a, b).

The area $\left(\mu \mathrm{m}^{2}\right)$ covered by CART-ir cells was estimated from the transverse sections passing through the PVN, PeA, $\mathrm{ARC}, \mathrm{PeF}$, and EW from the isolation reared and OBX rats. CART-ir fibers from these areas and also from PFC, CeA, and LC were separately assessed. In Figures 3-7 and Supplementary Figures S1-S3, the rectangular areas demarcate the regions from which the CART-ir cell and fiber area were evaluated. The procedure has already been described (Dandekar et al, 2008a, b).

\section{Statistical Analyses}

The data are presented as means \pm SEM. The statistical significance for the dose-dependent study of CART in normal and socially isolated animals were separately determined by one-way analysis of variance (ANOVA) with repeated measures on drug treatments followed by post hoc 
Dunnett's test. The behavioral data following social isolation and OBX experiments, as well as the morphometric data based on immunocytochemistry, was compared by unpaired $t$-test. The data for the dose-dependent study of CART in sham-operated and OBX animals were analyzed using two-way ANOVA followed by post hoc Bonferroni multiple comparisons test, where the surgery (sham and OBX) and drug treatment were the first and second factors. Individual group differences were further assessed with the one-way ANOVA followed by post hoc Student-NewmanKeuls test. Differences were considered significant at $P<0.05$.

\section{RESULTS}

\section{Effect of CART in the FST and Actophotometer}

Intracerebroventricular injection of CART, at the dose of 50 and $100 \mathrm{ng}$ per rat, significantly decreased the immobility duration $(\mathrm{F}(3,32)=18.830, P<0.0001)$ in FST by 18 and $41 \%$, respectively, and the change was found to be
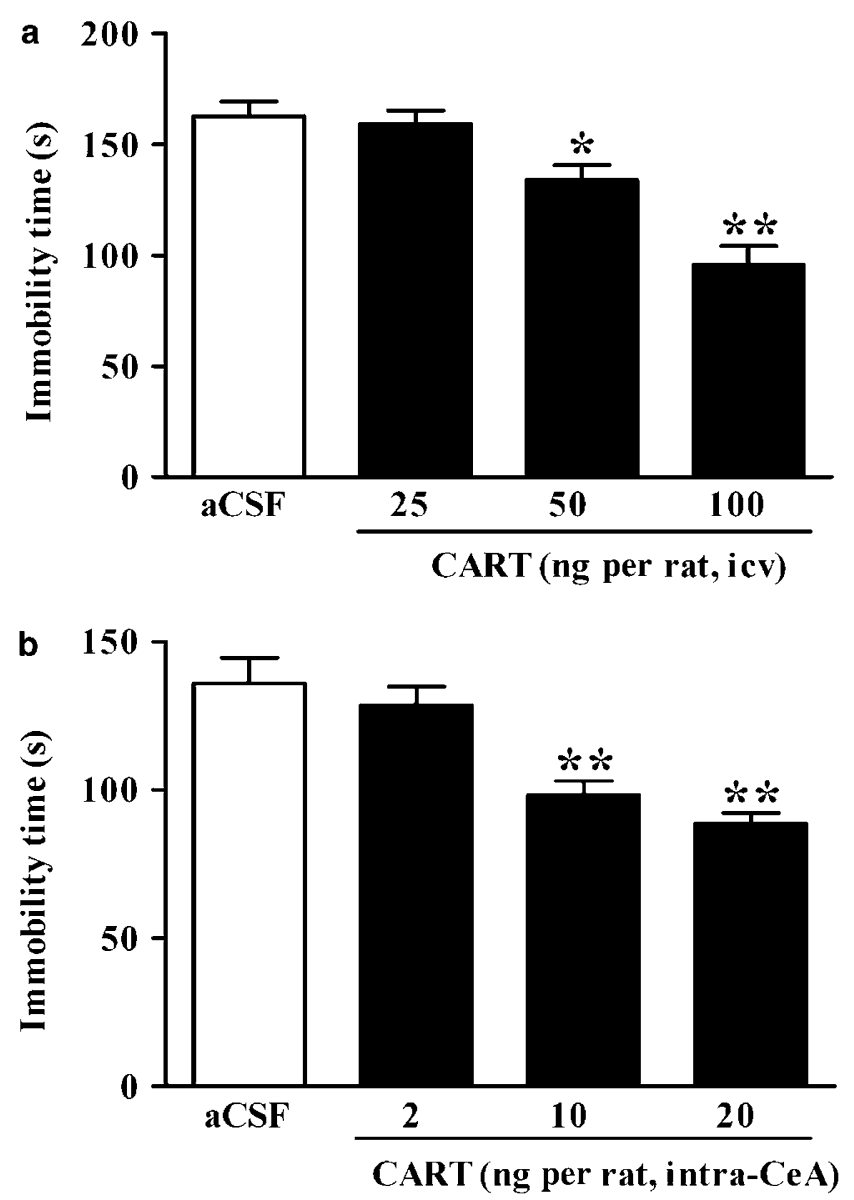

Figure I Effect of different doses of cocaine- and amphetamineregulated transcript peptide (CART) (54-102) administered via intracerebroventricular (icv) (a) or intra-central nucleus of amygdala (CeA) (b) route on immobility time of normal rat in 5 min forced swim test (FST). CART was microinjected through icv or intra-CeA route $30 \mathrm{~min}$ before the test. The data were analyzed by one-way analysis of variance (ANOVA) with repeated measures on drug treatments followed by post hoc Dunnett's test. Each bar is the mean \pm SEM for $6-9$ rats. $* P<0.05$ and $* * P<0.0$ I vs artificial cerebrospinal fluid (aCSF)-treated group. statistically significant $(P<0.05$ and $P<0.01$, respectively; Figure 1a). Similarly, at the doses of 10 and $20 \mathrm{ng}$ per rat by intra-CeA route, significantly and dose dependently reduced the immobility time $(\mathrm{F}(3,26)=15.120, P<0.0001)$ by 25 and $32 \%$, respectively. The altered immobility time by CART was significantly less $(P<0.01$ in both cases $)$ as compared with that in the aCSF-treated group (Figure 1b). Moreover, following icv or intra-CeA injections of CART, the animals were subjected to locomotor test using the actophotometer. None of these treatments caused any effect on the locomotor activity $(P>0.05)$.

\section{Effect of CART in Socially Isolated Rats in FST}

Social isolation for a period of 6 weeks showed a significant increase in the immobility time in both icv and intra-CeA aCSF treated animals (unpaired $t$-test; $t=4.275$, d.f. $=13$, $P<0.0009$ and $t=4.766$, d.f. $=12, P<0.0005$, respectively) as compared with the paired rats in the FST (Figure 2a and $b$ ), suggesting depression-like condition. Intracerebroventricular injection of CART, at the doses of 100 and $150 \mathrm{ng}$ per rat, significantly decreased the immobility duration $(F(3,26)=20.599, P<0.0001)$ in the socially isolated animals and the change was found to be statistically significant $(P<0.01$ in both cases; Figure 2a). Similarly, at the doses of 10 and $20 \mathrm{ng}$ per rat by intra-CeA route, CART significantly and dose dependently reduced the immobility time $(\mathrm{F}(3,34)=24.382, P<0.0001)$ in socially isolated rats in the FST. The altered immobility time following CART treatment was significantly less $(P<0.01$ in both cases) as compared with that in the aCSF-treated group (Figure $2 b$ ). Furthermore, immobility time observed following icv or intra-CeA CART treatment in socially isolated was similar to that in normal group housed animals (Figure $2 \mathrm{a}$ and $\mathrm{b}$ ), indicating reversal of depression-like behavior. None of these treatments showed any effect on the locomotor activity performed using the actophotometer $(P>0.05)$.

\section{Effect of CART in OBX Rats in OFT}

Significant increase in the activity (in terms of ambulation, rearing, grooming, and defecation scores) was observed in the OBX animals subjected to OFT on day 14 of postsurgery as compared with the sham-operated animals (Table 1). This clearly suggested the development of depression-like phenotype. Following 7 days of either subchronic icv (25$200 \mathrm{ng}$ per rat) or bilateral intra-CeA (2-40 ng per rat) CART infusion, rearing and grooming scores were significantly decreased as compared with those in the OBX group receiving aCSF. This suggests the reversal of hyperactivity in the OBX animals following subchronic treatment of CART given by icv or intra-CeA route. However, icv or intra-CeA treatment of CART at same doses and duration did not alter above-mentioned behavioral responses in the sham-operated animals $(P>0.05$; Table 1). Application of two-way ANOVA followed by post hoc Bonferroni multiple comparisons test revealed significant effect of surgery (sham/OBX) $(\mathrm{F}(1,54)=15.95$, $P<0.001$ or $\mathrm{F}(1,46)=6.97, P<0.05)$, and CART treatment $(\mathrm{F}(3,54)=5.18, P<0.01$ or $\mathrm{F}(3,46)=4.06, P<0.05)$ and interaction between factors CART treatment and surgery $($ sham/OBX $)(\mathrm{F}(3,54)=8.05, P<0.001$ or $\mathrm{F}(3,46)=6.18$, 

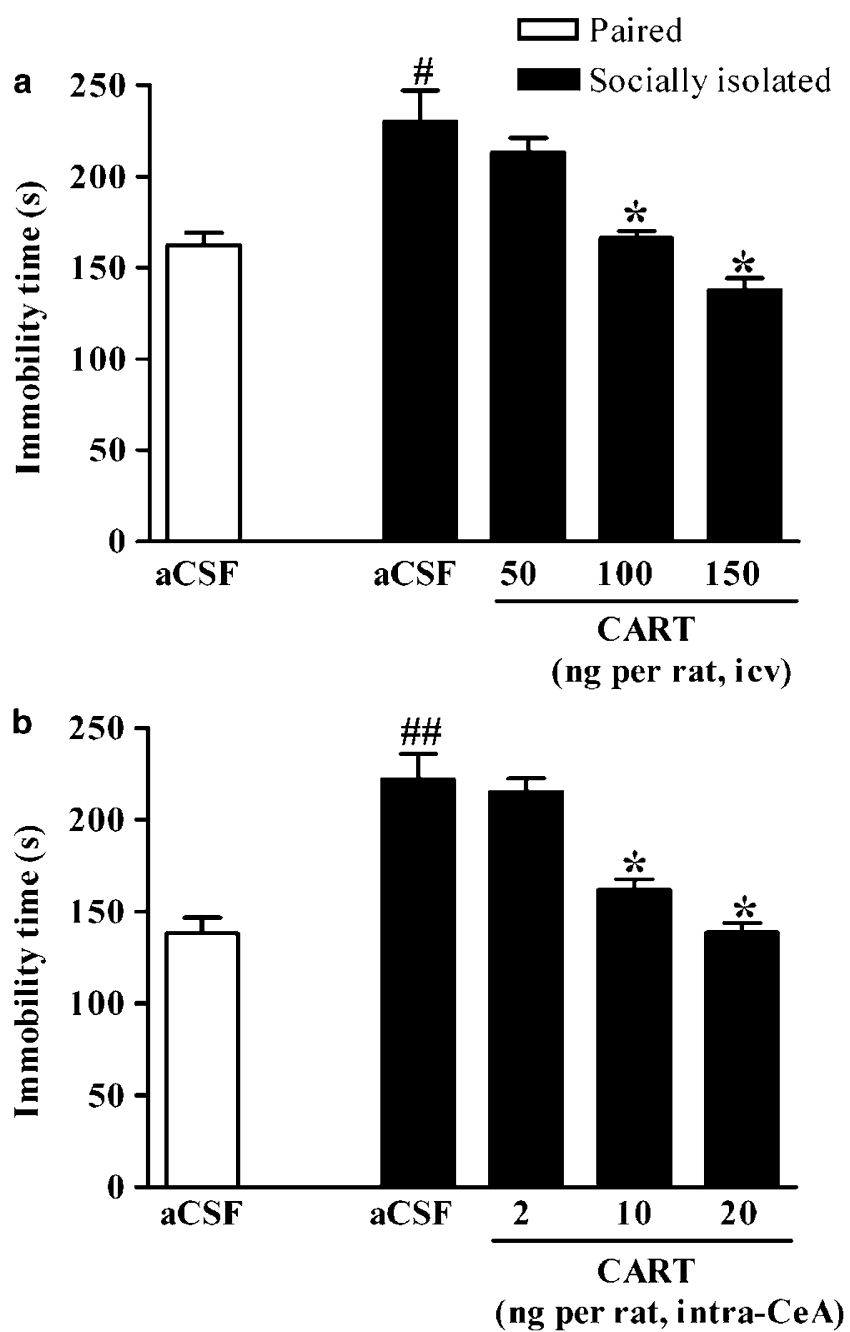

Figure 2 Effect of intracerebroventricular (icv) (a) or intra-central nucleus of amygdala (CeA) (b) treatment of artificial cerebrospinal fluid (aCSF) in the paired and 6 weeks socially isolated rats, and dose-dependent effect of cocaine- and amphetamine-regulated transcript peptide (CART) (54-102) administered by the same routes to the socially isolated rats. The immobility time was assessed using forced swim test (FST) for 5 min duration. aCSF or CART was microinjected through icv or intra-CeA route 30 min before the test in the 6 weeks socially isolated or paired animals. The data obtained from paired and socially isolated animals following aCSF treatment were analyzed by unpaired $t$-test. The data from different doses of CART treatments were analyzed by one-way analysis of variance (ANOVA) with repeated measures on drug treatments followed by post hoc Dunnett's test. Each bar is the mean \pm SEM for 6-9 rats. ${ }^{\#} P<0.0009$ and ${ }^{\# \#} P<0.0005$ vs paired group. ${ }^{*} P<0.01$ vs respective aCSF-treated socially isolated group.

$P<0.01)$ on the rearing score, following subchronic icv or intra-CeA CART treatment, respectively. However, two-way ANOVA revealed nonsignificant effects of surgery $(\mathrm{F}(1,54)=2.92, P>0.05$ or $\mathrm{F}(1,46)=2.35, P>0.05)$ and CART administration $(\mathrm{F}(3,54)=1.06, \quad P>0.05 \quad$ or $\mathrm{F}(3,46)=1.11, P>0.05)$, and significant interaction between factors CART treatment and surgery $(\mathrm{F}(3,54)=9.29$, $P<0.001$ or $\mathrm{F}(3,46)=5.07, P<0.01)$ on the grooming score, following subchronic icv or intra-CeA CART administration, respectively. However, no significant change $(P>0.05)$ was noticed in ambulation and defecation scores in OBX rats (Table 1 ).

\section{Effect of OBX and Social Isolation on CART-Immunoreactivity}

The paraventricular nucleus. Changes in the immunocytochemical profile of the CART-ir cells as well as fibers in the PVN of the various groups of rats, and their morphometric analyses are summarized in Figure 3. Although the CART-immunoreactivity in cells in the PVN was drastically reduced on day 14 of OBX as compared with the sham-operated animals (unpaired $t$-test, $P<0.0001$ ), CART-ir profile in the fibers remained unchanged (Figure $3 a, b$, and e). However, there was a dramatic decrease in CART-ir profile of cells (unpaired $t$-test, $P<0.0001$ ) and fibers (unpaired $t$-test, $P<0.002$ ) in the PVN of socially isolated (Figure $3 \mathrm{~d}$ ) as compared with the paired animals (Figure 3c-e).

The arcuate nucleus. Immunocytochemical profile of the CART-containing cells and fibers in the ARC of various groups of rats are shown in Figure 4. Although shamoperated rat showed several CART-ir cells and fibers (Figure 4a), considerable loss of immunoreactivity was noticed in cells (unpaired $t$-test, $P<0.0001$ ), but the profile of immunoreactive fibers did not change in OBX animals $(P>0.05$; Figure $4 \mathrm{~b}$ and e). Socially isolated rats showed similar pattern of CART-immunoreactivity; there was significant reduction in CART-ir cells (unpaired $t$-test, $P<0.0001$ ) but no change in fiber immunoreactivity following social isolation (Figure $4 c-e$ ).

The central nucleus of amygdala. Immunocytochemical application of antibodies against CART revealed few, weakly CART-ir fibers in the CeA of sham-operated (Figure 5a) as well as in paired rats (Figure 5c). However, a drastic increase in CART-immunoreactivity was noticed in OBX $(P<0.0005,112 \%$; Figure $5 \mathrm{~b}$ and $\mathrm{e})$ and socially isolated $(P<0.001,71 \%$; Figure $5 \mathrm{~d}$ and e) animals as compared with the respective controls.

The Edinger-Westphal nucleus. Changes in the immunocytochemical profile of the CART-ir cells in the EW of the various groups of rats, and their morphometric analysis are summarized in Figure 6. Considerable loss of immunoreactivity was noticed in cells in the OBX (unpaired $t$-test, $P<0.0001$ ) and socially isolated (unpaired $t$-test, $P<0.002$ ) as compared with the respective controls (Figure $6 \mathrm{a}-\mathrm{e}$ ).

The locus coeruleus. Immunocytochemical profile of the CART-containing fibers in the LC of various groups of rats, and their morphometric analyses are summarized in Figure 7. Although several CART-ir fibers were noticed in the LC of sham-operated or paired rats (Figure $7 \mathrm{a}$ and $\mathrm{c}$ ), a drastic decrease in CART-immunoreactivity was noticed in OBX (unpaired $t$-test, $P<0.001,38 \%$ ) and socially isolated animals (unpaired $t$-test, $P<0.0001,53 \%$ ) as compared with the respective control animals (Figure $7 b, d$, and e).

The periventricular area. Immunocytochemical application of antibodies against CART revealed moderate immunoreactivity in cells as well as fibers in the PeA of control rats. Changes in the immunocytochemical profile of the CARTimmunoreactive cells and fibers in the PeA of the various 
Table I Effect of Subchronic Treatment with CART in Sham-Operated or OBX Rats in OFT ${ }^{a}$

Score \pm SEM

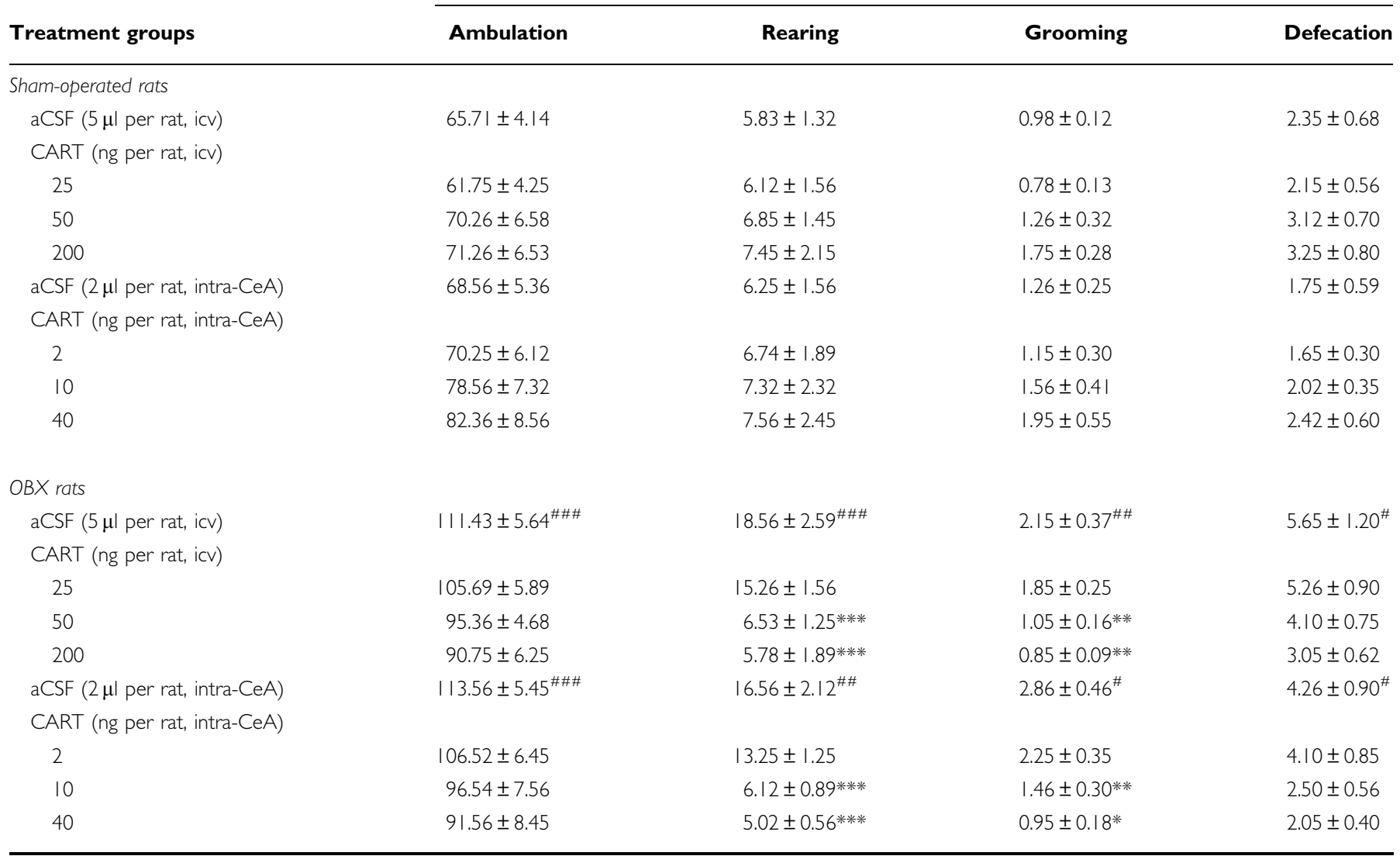

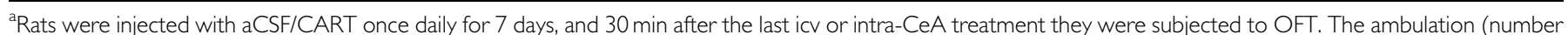
of crossovers), and rearing, grooming, and defecation (number of episodes) scores were counted for period of 3 min in OFT. The data represent mean of score \pm SEM for each group ( $n=6-8$ rats). The data were analyzed by two-way ANOVA followed by post hoc Bonferroni multiple comparisons test. Individual group differences

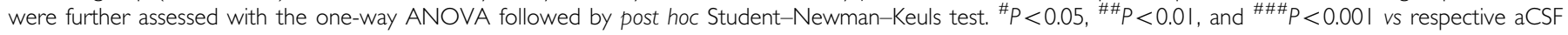
treated sham-operated control; $* P<0.05$, $* * P<0.0$ I, and $* * * P<0.00$ I vs respective aCSF treated OBX group.

groups of rats, and their morphometric analysis are summarized in Supplementary Figure S1. OBX did not influence the CART-ir profile $(P>0.05)$ in PeA as compared with that in the sham-operated animals. On the other hand, significant reduction in the CART-ir cells and augmentation in fibers (unpaired $t$-test, $P<0.0001$ in both cases) was observed in the socially isolated as compared with paired animals.

The perifornical nucleus. Immunocytochemical application of antibodies against CART revealed several intensely stained cells in the PeF of various groups of rats. As compared with sham-operated animals, bilateral ablation of the olfactory bulbs did not influence the CART-ir cells in PeF $(P>0.05)$. On the other hand, significant reduction in the CART-ir cells (unpaired $t$-test, $P<0.0001$ ) was observed in socially isolated as compared with paired animals (see Supplementary Figure S2).

The prefrontal cortex. Immunocytochemical application of antibodies against CART revealed few, scattered CART-ir fibers in the PFC of sham-operated, OBX, paired, and socially isolated rats. Population of CART-ir fibers appeared similar in all these groups. Morphometric analysis of the
CART-immunoreactivity in the PFC of the various groups of rats is summarized in Supplementary Figure S3.

\section{DISCUSSION}

\section{Methodological Considerations}

With a view to test the involvement of CART in depression, CART (54-102) was administered directly into the lateral ventricle and the behavioral response tested in FST. CART was also injected into the CeA, as this is known as a center for affective behaviors (Commons et al, 2003; Hwang et al, 2005; Dandekar et al, 2008a). Although Thim et al (1998) reported similar biological effects of CART fragments 54102 and 55-102, anxiogenic-like effect was exhibited by both the fragments (Chaki et al, 2003; Dandekar et al, 2008a). OBX produces several behavioral and neurochemical changes in the CNS of rat reminiscent of symptoms of human depression (Song et al, 1996; Kelly et al, 1997; Song and Leonard, 2005). OBX animals showed hyperactivity (increase in the ambulation, rearing, grooming, and defecation scores), which was assessed employing OFT as reported earlier (Song et al, 1996; Kelly et al, 1997; Song and Leonard, 2005). Although OFT is used to study the anxiety- 
like behavior in rodents, it is also routinely employed in the assessment of depression-like behavior in OBX animals (Song et al, 1996; Kelly et al, 1997; Song and Leonard, 2005). Similarly, 6 weeks social isolation and/or separation in rodents and primates have also been used to model human affective disorders (Koob et al, 1989). Socially isolated rats were subjected to FST for the assessment of depression-like phenotype. The period of 6 weeks was allowed as peak depression-like behavior was reported at this time point in
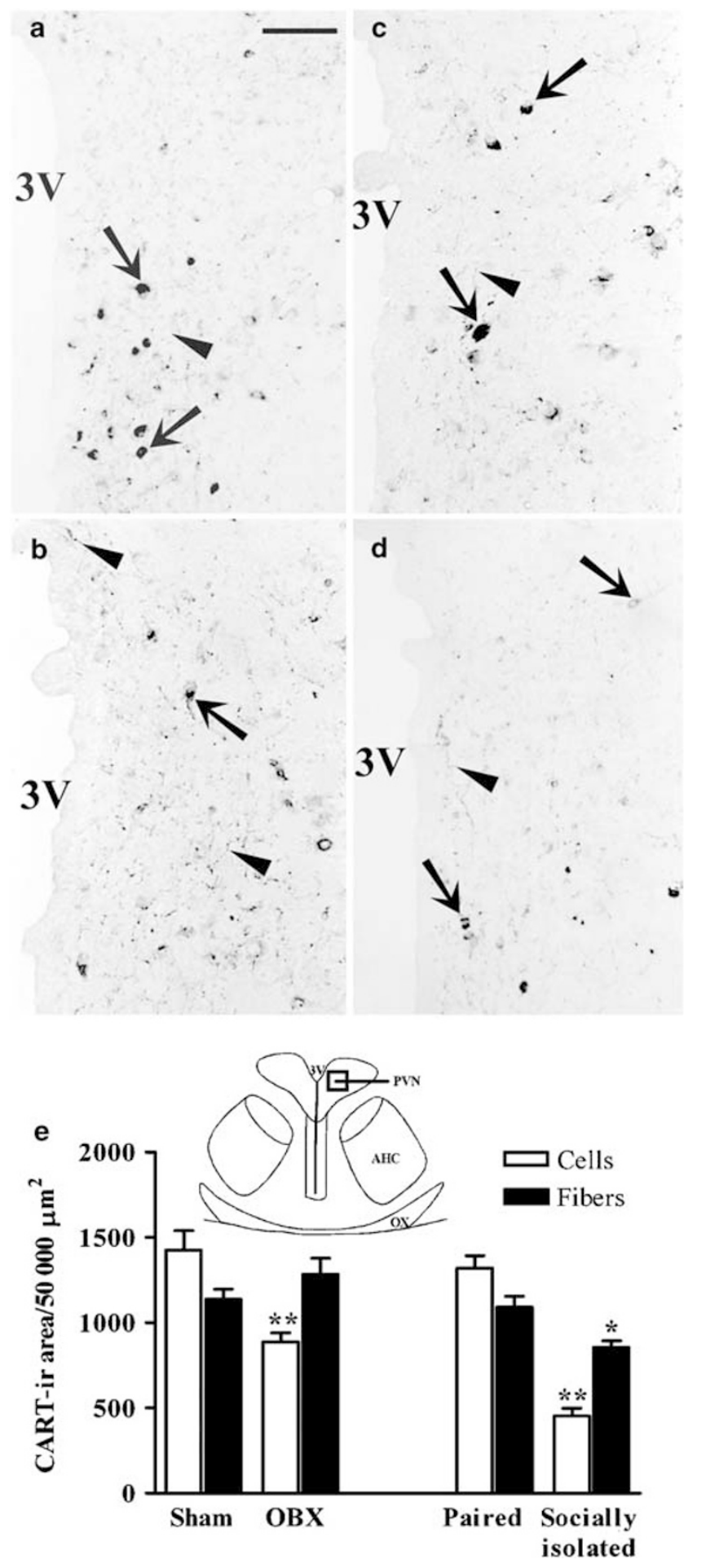

socially isolated animals (Ruedi-Bettschen et al, 2004; Brenes Saenz et al, 2006). Herein both the models were employed for generating the depression-like phenotype. In addition, CART (via icv and intra-CeA routes) was given in acute and subchronic protocols, to socially isolated and OBX rats respectively, and behavior responses were examined in terms of depression-like behaviors. CARTimmunoreactivity profiles in different components that process depression-related information were investigated. Although the immunocytochemistry technique revealed site-specific responses, application of morphometric analysis permitted the evaluation of relative quantitative changes following different experimental manipulations such as social isolation and OBX.

\section{Effect of icv and Intra-CeA Administration of CART on Depression-Like Behavior}

This study for the first time showed that icv administration of CART dose dependently resulted in antidepressant-like behavior in the FST; the locomotion component was unaffected. Similar response was noticed following intraCeA treatment of the peptide at a lower dose. CARTimmunoreactive fibers have already been demonstrated in the amygdala of rat (Koylu et al, 1998). Previously, we reported the participation of CART in the regulation of ethanol withdrawal induced anxiety-like behavior within the framework of CeA (Dandekar et al, 2008a). Taken together, the data suggest that endogenous CART may be involved in the regulation of depression-like behaviors possibly via CeA. These findings are supported by the observation that adolescents carrying a missense mutation in the CART gene exhibited anxiety and depression (Miraglia del Giudice et al, 2006). Interestingly, chronic mild stress downregulated the CART gene in the frontal cortex of rat (Orsetti et al, 2008). Pae et al (2007) commented on the therapeutic usefulness of CART in the treatment of depression. In recent years, Ma et al (2007) observed that CART-(61-102 or 62-76) increased the extracellular 5-HT, and speculated that the effect may be responsible for antidepressant-like action of CART. Furthermore, CART influences the expression of a range of neurotransmitters such as $\gamma$-aminobutyric acid, 5-HT, noradrenaline (NA), and dopamine that directly regulate affective disorders including depression

Figure 3 Photomicrographs showing cocaine- and amphetamine-regulated transcript peptide immunoreactive (CART-ir) cells (arrows) and fibers (arrowheads) in the hypothalamic paraventricular nucleus (PVN) of shamoperated (sham, (a)), olfactory bulbectomy (OBX, (b)), group housed (paired, (c)), and social isolated for 6 weeks (socially isolated, (d)) rats. Note a dramatic decrease in CART-ir cells in the PVN of the OBX (b) and socially isolated (d) as compared with sham and paired rats, respectively. Although there is no change in the CART-ir fibers in the OBX animals as compared with sham, a significant decrease in CART-ir fibers is observed in the socially isolated as compared with paired animals. Diagram (e) represents the semiquantitative morphometric analysis of CART-immunoreactivity in the PVN of sham, OBX, paired, and socially isolated animals. The outline of the transverse section through the brain (coordinate: bregma $-1.80 \mathrm{~mm}$; Paxinos and Watson, 1998) indicates the region of the PVN (square, not to scale) from which the measurements were collated. AHC, central part of anterior hypothalamic nucleus; ox, optic chiasma; $3 \mathrm{~V}$, third ventricle. The bar values are shown as the mean \pm SEM for $6-8$ rats. $* P<0.002$ vs paired and $* * * 0.000$ I vs sham and paired group. Scale bar $=200 \mu \mathrm{m}$. 

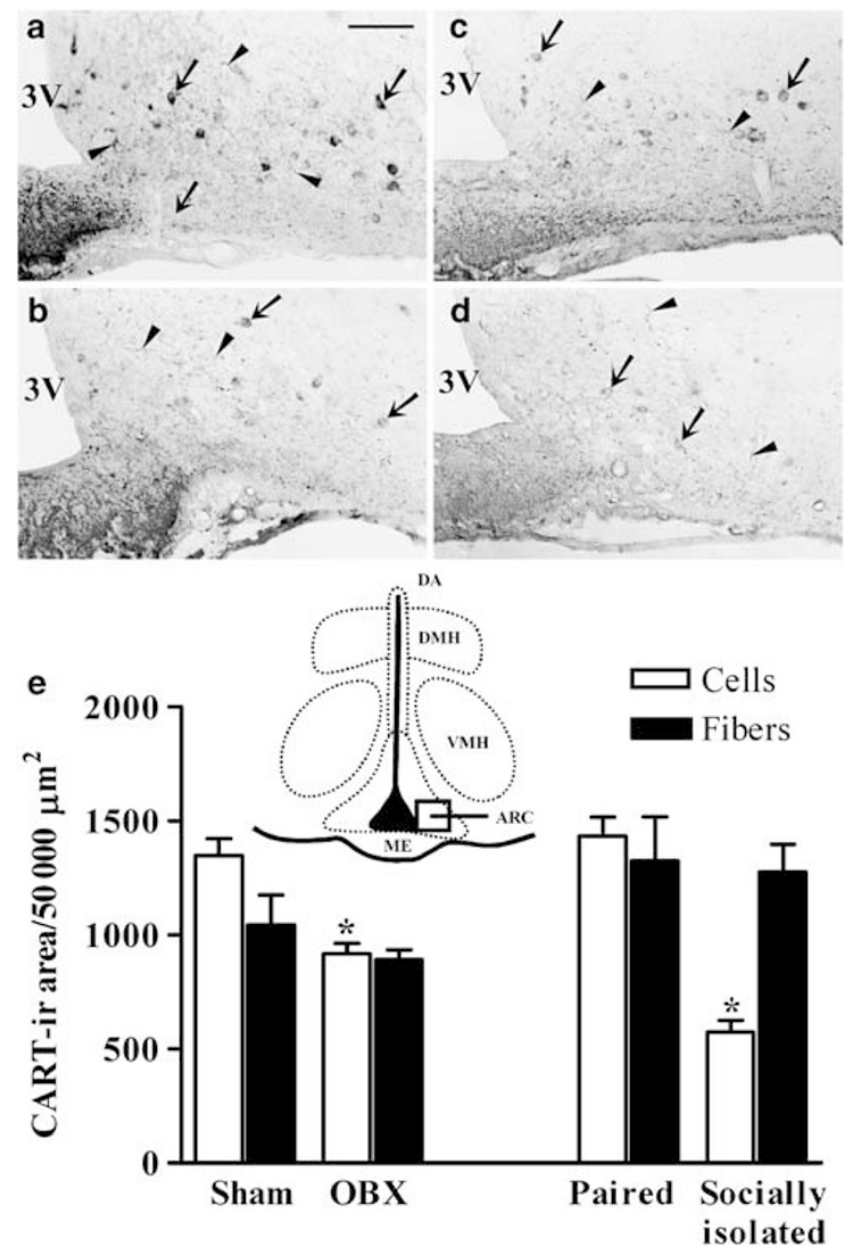

Figure 4 Photomicrographs showing cocaine- and amphetamineregulated transcript peptide immunoreactive (CART-ir) cells (arrows) and fibers (arrowheads) in the arcuate nucleus (ARC) of the shamoperated (sham, (a)), olfactory bulbectomy (OBX, (b)), group housed (paired, (c)), and social isolated for 6 weeks (socially isolated, (d)) rats. Note a dramatic decrease in CART-immunoreactivity in the neurons of the $A R C$ in the OBX (b) and socially isolated (d) as compared with sham and paired rats, respectively. No change in CART-ir fibers is noticed. Diagram (e) represents the semiquantitative morphometric analysis of CARTimmunoreactivity in the ARC of sham, OBX, paired, and socially isolated animals. The outline of the transverse section through the brain (coordinate: bregma $-2.56 \mathrm{~mm}$; Paxinos and Watson, 1998) indicates the region of the ARC (square, not to scale) from which the measurements were collated. DA, dorsal hypothalamic area; $\mathrm{DMH}$, dorsal part of dorsomedial hypothalamus; $3 \mathrm{~V}$, third ventricle; $\mathrm{VMH}$, ventromedial hypothalamic nucleus; and ME, median eminence. The bar values are shown as the mean \pm SEM for $6-8$ rats. ${ }^{*} P<0.000$ I vs sham or paired group. Scale bar $=200 \mu \mathrm{m}$.

(Vaarmann and Kask, 2001; Choi et al, 2003; Yang et al, 2004; Hunter et al, 2006; Jaworski et al, 2007; Ma et al, 2007), and it is possible that antidepressant action of CART may be mediated via some of these neurotransmitters.

\section{Effect of CART on Depression-Like Conditions Generated following Social Isolation and OBX}

Significant increase in immobility time was observed in the social isolated rats, reflecting the depression-like pheno-

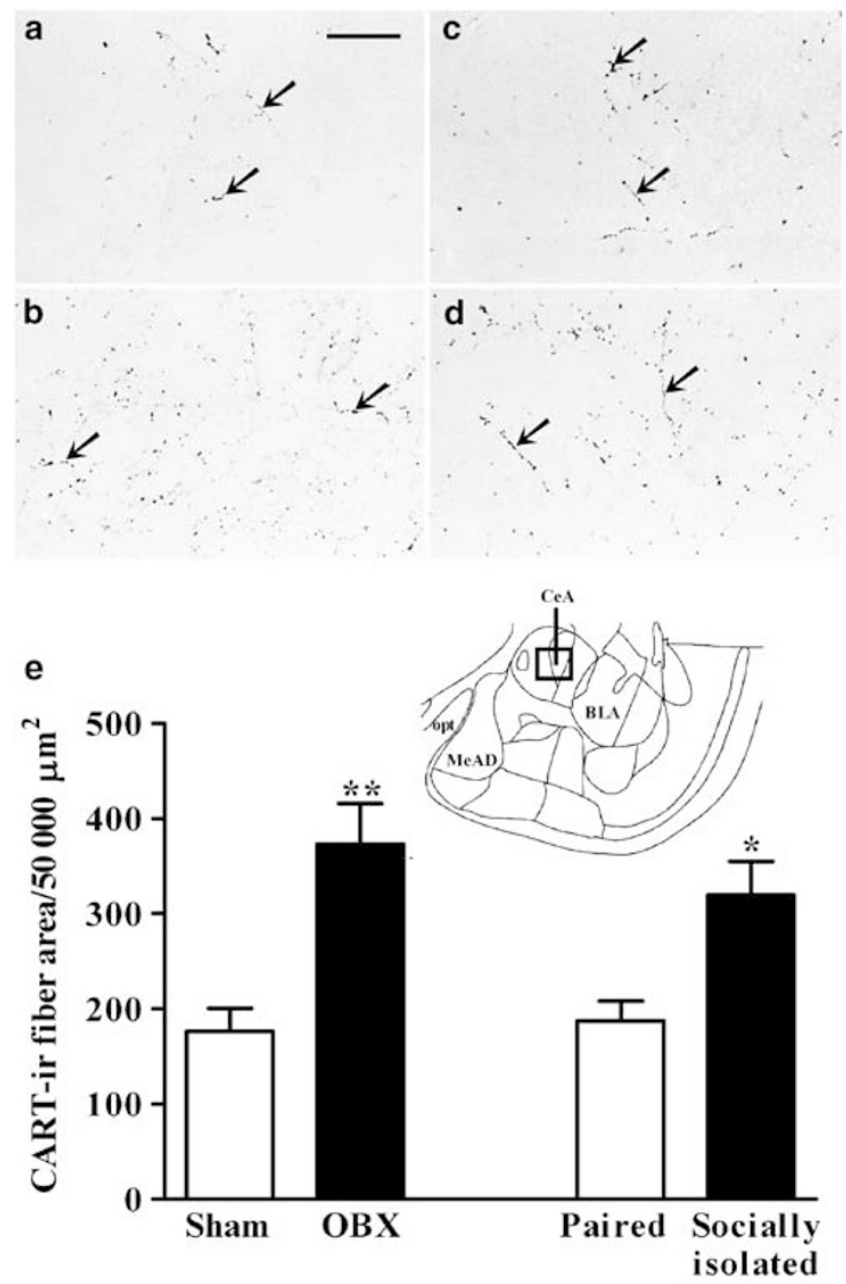

Figure 5 Photomicrographs showing cocaine- and amphetamineregulated transcript peptide immunoreactive (CART-ir) fibers (arrows) in the central nucleus of amygdala (CeA) of sham-operated (sham, (a)), olfactory bulbectomy (OBX, (b)), group housed (paired, (c)), and social isolated for 6 weeks (socially isolated, (d)) rats. A dramatic increase in CART-immunoreactivity is seen in both OBX (b) and socially isolated (d) as compared with sham and paired animals, respectively. Diagram (e) represents the semiquantitative morphometric analysis of CART-immunoreactivity in the $\mathrm{CeA}$ of sham, $\mathrm{OBX}$, paired, and socially isolated animals. The outline of the transverse section through the brain (coordinate: bregma $-2.56 \mathrm{~mm}$; Paxinos and Watson, 1998) indicates the region of the $\mathrm{CeA}$ (square, not to scale) from which the measurements were collated. BLA, lateral part of basolateral amygdaloid nucleus; MeAD, anterodorsal part of medial amygdaloid nucleus; and opt, optic tract. The bar values are shown as the mean \pm SEM for $6-8$ rats. $* P<0.001$ vs paired group and ** $P<0.0005$ vs sham-operated group. Scale bar $=50 \mu \mathrm{m}$.

type. The behavioral observation following social isolation is in accordance with previous reports (Ruedi-Bettschen et al, 2004; Shabanov and Roik, 2005). Although higher doses of CART via icv route brought the elevated immobility time to control value, the doses used in normal animals produced reduction in immobility time following intra-CeA CART in the socially isolated animals. Similarly, higher dose of ethanol was required to produce anxiolyticlike action in the 6 weeks socially isolated animals (Hirani et al, 2005). These behavioral findings can be correlated with the immunocytochemistry results of this study. We 
observed reduced CART-immunoreactivity in the PVN, PeA, ARC, PeF, EW, and LC following social isolation in rats. These results suggest that icv and intra-CeA treatments of CART may reverse the depression-like behavior observed following 6 weeks of social isolation.
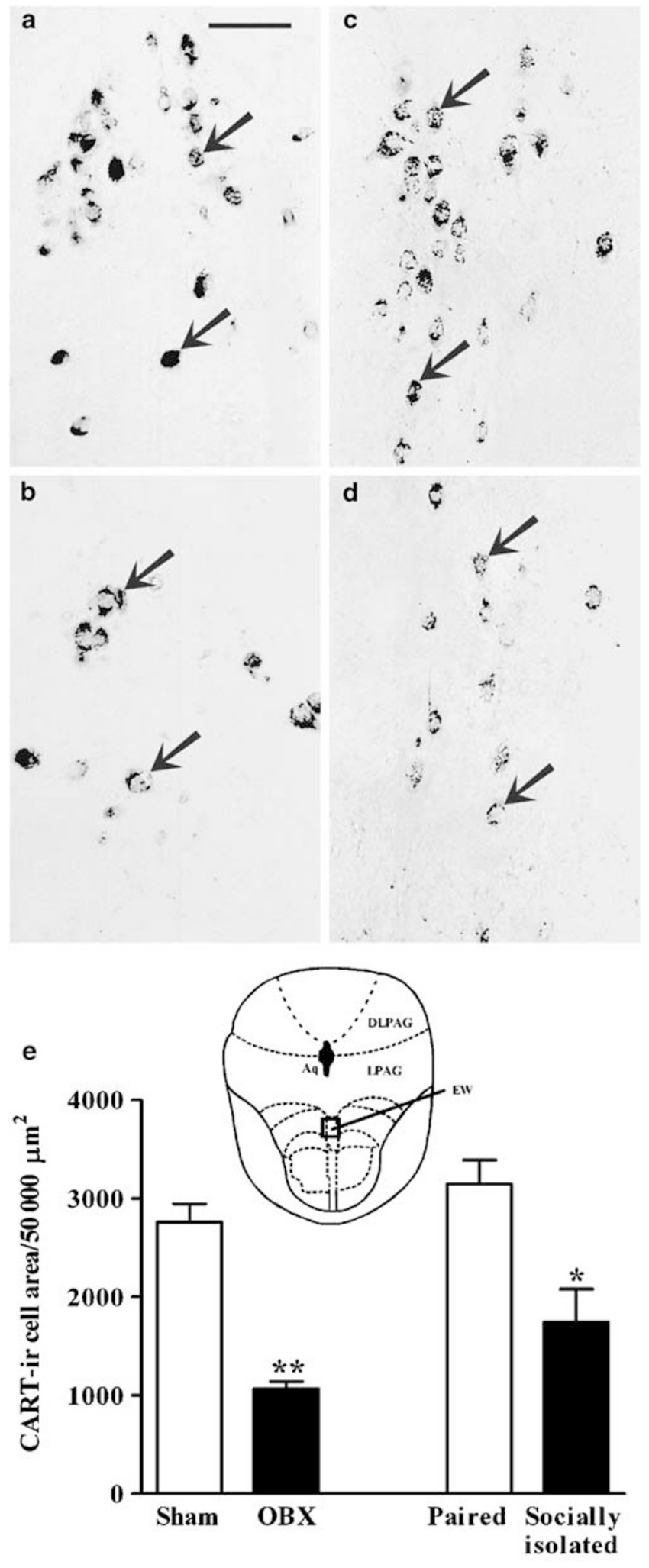

Our observations showed hyperactivity (increased ambulation, rearing, grooming, and defecation scores) in the OBX animals, indicating development of marked depression-like behavior in OBX rats. Several studies demonstrated that most of the behavioral changes observed in the OBX rat are reversed by chronic, but not acute, antidepressant treatments (Kelly et al, 1997; Song and Leonard, 2005). Moreover, increased rearing and grooming scores in $\mathrm{OBX}$ animals have been attenuated following 7 days icv administration of neuropeptide Y (NPY) and interleukin-2 (Song and Leonard, 1995; Song et al, 1996). In this study also subchronic treatment of CART, via icv or intra-CeA route, for 7 days attenuated the hyperactive behavior of OBX rats, which was indicated by significant decrease of rearing and grooming scores in OFT. However, similar doses and route of administrations of CART did not alter the behavioral responses in the sham-operated animals. These results suggest that icv and intra-CeA treatments of CART may reverse the depression-like behavior observed following OBX surgery in rats.

\section{Effect of OBX and Social Isolation on CART-Immunoreactivity}

CART-immunoreactivity in the PVN, ARC, EW, and LC regions was significantly reduced following social isolation as well as OBX. A number of actions of CART are attributed to its interaction with the corticotropin-releasing hormone (CRH) system of the PVN (Sarkar et al, 2004). CART as well as $\mathrm{CRH}$ have been reported to be involved in depression (Owens and Nemeroff, 1993; Ma et al, 2007; Orsetti et al, 2008). This result suggests that CART in the PVN may be a novel component that mediates some of the effects triggered by social isolation and $\mathrm{OBX}$ in rats.

Although CART-ir cells significantly reduced, fibers remained unchanged in the ARC in both isolation reared and OBX animals. Several studies have demonstrated the participation of ARC neurons in the regulation of depression-like behavior. Acute and chronic stress, which produces depression-like state, increased NPY mRNA expression in the ARC of rat (Makino et al, 2000; Sergeyev et al, 2005). Significant increase in NPY and pro-opiomelanocortin mRNA levels in the ARC were observed following chronic treatment with the antidepressant drugs such as imipramine, fluoxetine, phenelzine, and idazoxan (Baker

Figure 6 Photomicrographs showing cocaine- and amphetamine-regulated transcript peptide immunoreactive (CART-ir) cells (arrows) in the Edinger-Westphal (EW) nucleus of sham-operated (sham, (a)), olfactory bulbectomy (OBX, (b)), group housed (paired, (c)), and social isolated for 6 weeks (socially isolated, (d)) rats. A dramatic decrease in CARTimmunoreactivity is apparent in both $\mathrm{OBX}(\mathrm{b})$ and socially isolated (d) as compared with sham and paired animals, respectively. Diagram (e) represents the semiquantitative morphometric analysis of CART-immunoreactivity in the EW of sham, OBX, paired, and socially isolated animals. The outline of the transverse section through the brain (coordinate: bregma $-6.80 \mathrm{~mm}$; Paxinos and Watson, 1998) indicates the region of the EW (square, not to scale) from which the measurements were collated. DLPAG, dorsolateral periaqueductal gray; LPAG, lateral periaqueductal gray; and Aq, aqueduct of sylvius. The bar values are shown as the mean \pm SEM for $6-8$ rats. $* P<0.002$ vs paired group and $* * P<0.000$ I vs sham group. Scale bar $=200 \mu \mathrm{m}$. 
et al, 1996). It is possible that decrease in CART in the ARC neurons observed in this study may be functionally linked to depression-like phenotype following social isolation and OBX.

The changes in CART-ir profile in the PVN, ARC, EW, LC, and CeA permit some interesting conclusions. Although OBX and 6 weeks of social isolation drastically reduced CART-immunoreactivity in the neurons of the PVN and the ARC, the fiber population in the CeA was dramatically
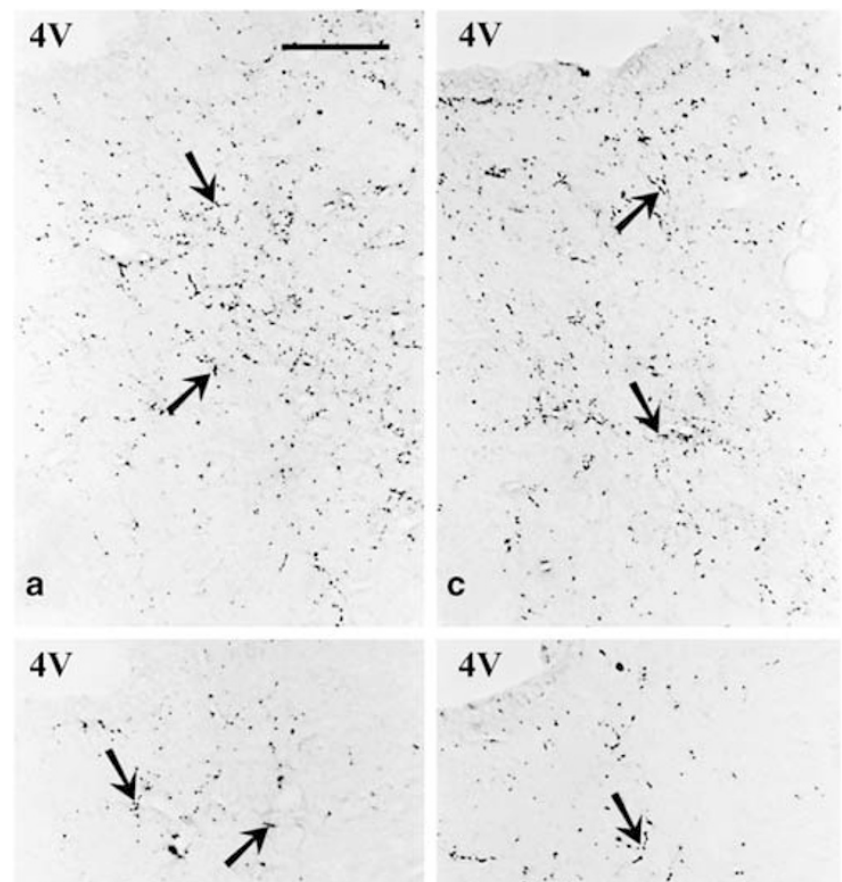

b
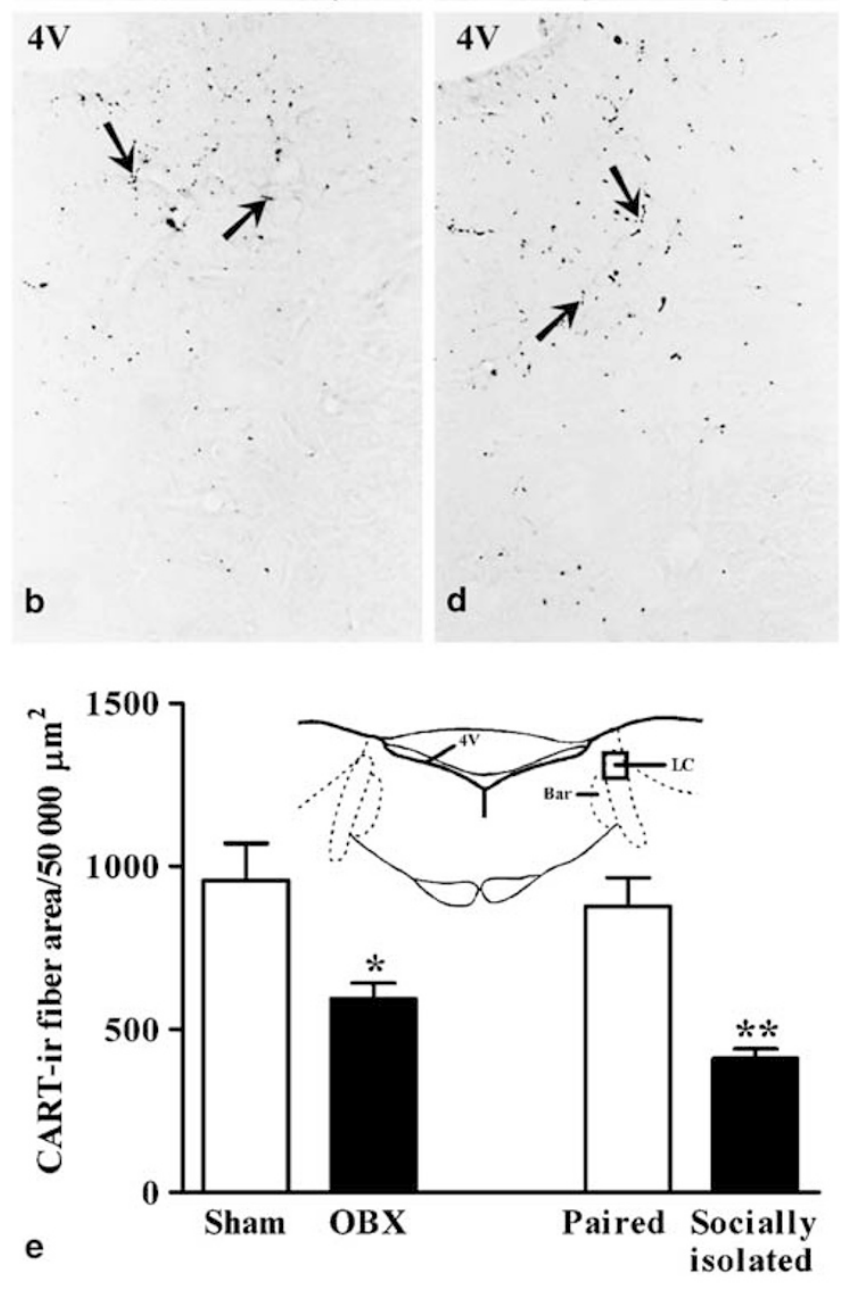

augmented. We suggest that these events may be causally linked. The application of OBX as well as social isolation might promote anterograde transport of CART from the PVN and ARC neuronal cell bodies to the CeA and that the elevation of CART in the CeA might be the key factor in the regulation of depression-like behavior. This concept is supported by the circumstantial evidences such as (1) demonstrated role of PVN and ARC neurons in depression (Baker et al, 1996; Makino et al, 2000; Kim et al, 2003; Sergeyev et al, 2005), (2) occurrence of neuronal connectivity from the PVN and ARC to the amygdala (Eskay et al, 1979; O'Donohue et al, 1979; Cone, 2005), (3) the recognition of amygdala as a site for processing of the depression-related information (Aggleton, 1993; Song et al, 1996; Huang and Lin, 2006; Dannlowski et al, 2008), (4) increase in the CART content in the CeA of rat and its importance in ethanol withdrawal-induced anxiety-like behavior (Dandekar et al, 2008a), (5) our observation that direct injection of CART into the CeA resulted in antidepressant-like effect in the normal rat, and (f) that the depression-like conditions in the socially isolated and OBX animals were reversed by intra-CeA CART treatment. Moreover, the possibility of upregulation of CART expression locally in the CeA following social isolation and OBX may not be ruled out. The expression of CART mRNA in the CeA region following acute and chronic restraint stress has already been reported by Hunter et al (2007). Amygdala is a center critical for the regulation of several psychological behaviors including depression (Aggleton, 1993). More recently, increased CART level was reported in the amygdala of rats following forced swim and acute stress (Balkan et al, 2006; Hunter et al, 2007). Orsetti et al (2008) reported downregulation of CART gene in the frontal cortex of rat following chronic mild stress. However, in this study no changes were seen in the CART-immunoreactivity profile in the PFC following social isolation and OBX.

Following social isolation as well as OBX, reduction in the CART-immunoreactivity was clearly seen in the neurons of EW and fibers of LC, and the possibility exits that this may also be linked to the phenomenon of depression. Circumstantial evidence supports such a view. Although the role of another peptide urocortin in depression is well documented (Tanaka and Telegdy, 2008), the peptide is known to colocalize with CART in the EW neurons (Kozicz, 2003). The reduction in CART-immunoreactivity in the fibers of the LC region is an interesting observation. It is possible

Figure 7 Photomicrographs showing CART-immunoreactive (CART-ir) fibers (arrows) in the locus coeruleus (LC) of sham-operated (sham, (a)), olfactory bulbectomy (OBX, (b)), group housed (paired, (c)), and social isolated for 6 weeks (socially isolated, (d)) rats. A dramatic decrease in CART-immunoreactivity is apparent in both OBX (b) and socially isolated (d) as compared with sham and paired animals, respectively. Diagram (e) represents the semiquantitative morphometric analysis of CART-immunoreactivity in the LC of sham, OBX, paired, and socially isolated animals. The outline of the transverse section through the brain (coordinate: bregma $-9.68 \mathrm{~mm}$; Paxinos and Watson, 1998) indicates the region of the LC (square, not to scale) from which the measurements were collated. $4 \mathrm{~V}$, fourth ventricle; Bar, Barrington's nucleus. The bar values are shown as the mean \pm SEM for $6-8$ rats. $* P<0.00$ I vs sham-operated and $* * P<0.000$ I vs paired group. Scale bar $=50 \mu \mathrm{m}$. 
that the CART fibers may innervate and influence the NA neurons of the LC. A role for these NA neurons in depression has been extensively reported (Stone et al, 2007).

Application of OBX and social isolation trigger changes in the CART-ir profile in several anatomical areas of the brain. Although those in the PeA and PeF showed reduction following social isolation, OBX did not cause any major change in these areas. This study provides a unique opportunity to compare two different models, OBX and social isolation, aimed at creating depression-like condition. It seems that reduction of CART in the PVN, ARC, EW, and $\mathrm{LC}$, and concurrent increase in the CeA in both the models might be a common underlying principle for the generation of depression. If that be the case, CART system might be the right target for treatment of depression, as already speculated by Pae et al (2007).

\section{ACKNOWLEDGEMENTS}

We thank Dr Lars Thim, Department of Assay and Cell Technology, Novo Nordisk A/S, Bagsvaerd, Denmark and Dr Jes Thorn Clausen, Department of Protein Chemistry, Novo Nordisk A/S, Bagsvaerd, Denmark for the generous gift of the CART peptide and antibody. This study was supported by the grant from the Department of Science and Technology (SR/SO/AS/40/2007), Government of India, New Delhi, India.

\section{DISCLOSURE/CONFLICT OF INTEREST}

The authors declare that except for income received from the primary employer no financial support or compensation has been received from any individual or corporate entity over the past 3 years for research or professional service and there are no personal financial holdings that could be perceived as constituting a potential conflict of interest.

\section{REFERENCES}

Aggleton JP (1993). The contribution of the amygdala to normal and abnormal emotional states. Trends Neurosci 16: 328-333.

Baker RA, Herkenham M, Brady LS (1996). Effects of long-term treatment with antidepressant drugs on proopiomelanocortin and neuropeptide $\mathrm{Y}$ mRNA expression in the hypothalamic arcuate nucleus of rats. J Neuroendocrinol 8: 337-343.

Balkan B, Gozen O, Yararbas G, Koylu EO, Akinturk S, Kuhar MJ et al (2006). CART expression in limbic regions of rat brain following forced swim stress: sex differences. Neuropeptides 40: 185-193.

Balkan B, Koylu E, Pogun S, Kuhar MJ (2003). Effects of adrenalectomy on CART expression in the rat arcuate nucleus. Synapse 50: 14-19.

Brenes Saenz JC, Villagra OR, Fornaguera Trias J (2006). Factor analysis of forced swimming test, sucrose preference test and open field test on enriched, social and isolated reared rats. Behav Brain Res 169: 57-65.

Chaki S, Kawashima N, Suzuki Y, Shimazaki T, Okuyama S (2003). Cocaine- and amphetamine-regulated transcript peptide produces anxiety-like behavior in rodents. Eur J Pharmacol 464: 49-54.

Choi SH, Kwon BS, Lee S, Houpt TA, Lee HT, Kim DG et al (2003). Systemic 5-hydroxy-L-tryptophan down-regulates the arcuate CART mRNA level in rats. Regul Pept 115: 73-80.
Commons KG, Connolley KR, Valentino RJ (2003). A neurochemically distinct dorsal raphe-limbic circuit with a potential role in affective disorders. Neuropsychopharmacology 28: 206-215.

Cone RD (2005). Anatomy and regulation of the central melanocortin system. Nature 8: 571-578.

Couceyro PR, Koylu EO, Kuhar MJ (1997). Further studies on the anatomical distribution of CART by in situ hybridisation. J Chem Neuroanat 12: 229-241.

Dandekar MP, Singru PS, Kokare DM, Lechan RM, Thim L, Clausen JT et al (2008a). Importance of cocaine- and amphetamine-regulated transcript peptide in the central nucleus of amygdala in anxiogenic responses induced by ethanol withdrawal. Neuropsychopharmacology 33: 1127-1136.

Dandekar MP, Singru PS, Kokare DM, Subhedar NK (2008b). Transient up-regulation of cocaine- and amphetamine-regulated transcript peptide (CART) immunoreactivity following ethanol withdrawal in rat hypothalamus. Brain Res; doi:10.1016/ j.brainres. 2008.09.023.

Dannlowski U, Ohrmann P, Bauer J, Deckert J, Hohoff C, Kugel H et al (2008). 5-HTTLPR biases amygdala activity in response to masked facial expressions in major depression. Neuropsychopharmacology 33: 418-424.

Dominguez G, Vicentic A, Del Giudice EM, Jaworski J, Hunter RG, Kuhar MJ (2004). CART peptides: modulators of mesolimbic dopamine, feeding, and stress. Ann N Y Acad Sci 1025: 363-369.

Douglass J, McKinzie AA, Couceyro P (1995). PCR differential display identifies a rat brain mRNA that is transcriptionally regulated by cocaine and amphetamine. J Neurosci 15: 2471-2481.

Eskay RL, Giraud P, Oliver C, Brown-Stein MJ (1979). Distribution of alpha-melanocyte-stimulating hormone in the rat brain: evidence that alpha-MSH-containing cells in the arcuate region send projections to extra-hypothalamic areas. Brain Res 178: 55-67.

Goyal SN, Kokare DM, Chopde CT, Subhedar NK (2006). Alphamelanocyte stimulating hormone antagonizes antidepressantlike effect of neuropeptide Y in Porsolt's test in rats. Pharmacol Biochem Behav 85: 369-377.

Hirani K, Sharma AN, Jain NS, Ugale RR, Chopde CT (2005). Evaluation of GABAergic neuroactive steroid $3 \alpha$-hydroxy- $5 \alpha$ pregnane-20-one as a neurobiological substrate for the anti-anxiety effect of ethanol in rats. Psychopharmacology 180: 267-278.

Huang TY, Lin CH (2006). Role of amygdala MAPK activation on immobility behavior of forced swim rats. Behav Brain Res 173: 104-111.

Hunter RG, Bellani R, Bloss E, Costa A, Romeo RD, McEwen BS (2007). Regulation of CART mRNA by stress and corticosteroids in the hippocampus and amygdala. Brain Res 1152: 234-240.

Hunter RG, Jones D, Vicentic A, Hue G, Rye D, Kuhar MJ (2006). Regulation of CART mRNA in the rat nucleus accumbens via D3 dopamine receptors. Neuropharmacology 50: 858-864.

Hwang BH, Katner J, Iyengar S (2005). Corticotropin-releasing factor mRNA and substance $P$ receptor binding in the paraventricular hypothalamic nucleus, central nucleus of the amygdala, and locus coeruleus of Sprague-Dawley rats following restraint-induced stress. J Mol Neurosci 25: 239-250.

Jaworski JN, Kimmel HL, Mitrano DA, Tallarida RJ, Kuhar MJ (2007). Intra-VTA CART 55-102 reduces the locomotor effect of systemic cocaine in rats: an isobolographic analysis. Neuropeptides 41: 65-72.

Jaworski JN, Vicentic A, Hunter RG, Kimmel HL, Kuhar MJ (2003). CART peptides are modulators of mesolimbic dopamine and psychostimulants. Life Sci 73: 741-747.

Jones DC, Kuhar MJ (2006). Cocaine-amphetamine-regulated transcript expression in the rat nucleus accumbens is regulated by adenylyl cyclase and the cyclic adenosine $5^{\prime}$-monophosphate/ 
protein kinase a second messenger system. J Pharmacol Exp Ther 317: 454-461.

Karim A, Arslan MI (2000). Isolation modifies the behavioural response in rats. Bangladesh Med Res Counc Bull 26: 27-32.

Kelly JP, Wrynn A, Leonard BE (1997). The olfactory bulbectomized rat as a model of depression: an update. Pharmacol Ther 74: 299-316.

Kim H, Whang WW, Kim HT, Pyun KH, Cho SY, Hahm DH et al (2003). Expression of neuropeptide $\mathrm{Y}$ and cholecystokinin in the rat brain by chronic mild stress. Brain Res 983: 201-208.

Kimmel HL, Gong W, Vechia SD, Hunter RG, Kuhar MJ (2000). Intra-ventral tegmental area injection of rat cocaine and amphetamine-regulated transcript peptide 55-102 induces locomotor activity and promotes conditioned place preference. J Pharmacol Exp Ther 294: 784-792.

Kokare DM, Chopde CT, Subhedar NK (2006). Participation of $\alpha$ melanocyte stimulating hormone in ethanol-induced anxiolysis and withdrawal anxiety in rats. Neuropharmacology 50: $536-545$.

Kokare DM, Dandekar MP, Chopde CT, Subhedar N (2005). Interaction between neuropeptide $\mathrm{Y}$ and alpha-melanocyte stimulating hormone in amygdala regulates anxiety in rats. Brain Res 1043: 107-114.

Kokare DM, Singru PS, Dandekar MP, Chopde CT, Subhedar NK (2008). Involvement of alpha-melanocyte stimulating hormone $(\alpha-\mathrm{MSH})$ in differential ethanol exposure and withdrawal related depression in rat: neuroanatomical-behavioral correlates. Brain Res 1216: 53-67.

Koob GF, Ehlers CL, Kupfer DJ (1989). Animal Models of Depression. Birkhauser: Boston.

Koylu EO, Balkan B, Kuhar MJ, Pogun S (2006). Cocaine and amphetamine regulated transcript (CART) and the stress response. Peptides 27: 1956-1969.

Koylu EO, Couceyro PR, Lambert PD, Kuhar MJ (1998). Cocaineand amphetamine-regulated transcript peptide immunohistochemical localization in the rat brain. J Comp Neurol 391: 115-132.

Koylu EO, Couceyro PR, Lambert PD, Ling NC, DeSouza EB, Kuhar MJ (1997). Immunohistochemical localization of novel CART peptides in rat hypothalamus, pituitary and adrenal gland. J Neuroendocrinol 9: 823-833.

Kozicz T (2003). Neurons colocalizing urocortin and cocaine- and amphetamine-regulated transcript immunoreactivities are induced by acute lipopolysaccharide stress in the EdingerWestphal nucleus in the rat. Neuroscience 116: 315-320.

Kristensen P, Judge ME, Thim L, Ribel U, Christjansen KN, Wulff BS et al (1998). Hypothalamic CART is a new anorectic peptide regulated by leptin. Nature 393: 72-76.

Kuhar MJ, Dall Vechia SE (1999). CART peptides: novel addiction and feeding-related neuropeptides. Trends Neurosci 22: 316-320.

Kuriyama G, Takekoshi S, Tojo K, Nakai Y, Kuhar MJ, Osamura RY (2004). Cocaine- and amphetamine-regulated transcript peptide in the rat anterior pituitary gland is localized in gonadotrophs and suppresses prolactin secretion. Endocrinology 145: 2542-2550.

Lakatos A, Prinster S, Vicentic A, Hall RA, Kuhar MJ (2005). Cocaine- and amphetamine-regulated transcript (CART) peptide activates the extracellular signal-regulated kinase (ERK) pathway in AtT20 cells via putative G-protein coupled receptors. Neurosci Lett 384: 198-202.

Ma Z, Pearson E, Tao R (2007). CART peptides increase 5hydroxytryptamine in the dorsal raphe and nucleus accumbens of freely behaving rats. Neurosci Lett 417: 303-307.

Makino S, Baker RA, Smith MA, Gold PW (2000). Differential regulation of neuropeptide $\mathrm{Y}$ mRNA expression in the arcuate nucleus and locus coeruleus by stress and antidepressants. J Neuroendocrinol 12: 387-395.
Miraglia del Giudice E, Santoro N, Fiumani P, Dominguez G, Kuhar MJ, Perrone L (2006). Adolescents carrying a missense mutation in the CART gene exhibit increased anxiety and depression. Depress Anxiety 23: 90-92.

O'Connor WT, Leonard BE (1988). Behavioural and neuropharmacological properties of the dibenzapines, desipramine and lofepramine: studies on the olfactory bulbectomized rat model of depression. Prog Neuro-Psychopharmacol Biol Psychiatry 12: 41-51.

O'Donohue TL, Miller RL, Jacobowitz DM (1979). Identification, characterization and stereotaxic mapping of intraneuronal alpha-melanocyte stimulating hormone-like immunoreactive peptides in discrete regions of the rat brain. Brain Res 176: 101-123.

Orsetti M, Di Brisco F, Canonico PL, Genazzani AA, Ghi P (2008). Gene regulation in the frontal cortex of rats exposed to the chronic mild stress paradigm, an animal model of human depression. Eur J Neurosci 27: 2156-2164.

Owens MJ, Nemeroff CB (1993). The role of corticotropin-releasing factor in the pathophysiology of affective and anxiety disorders: laboratory and clinical studies. Ciba Found Symp 172: 296-316.

Pae CU, Lee C, Paik IH (2007). Therapeutic implication of cocaineand amphetamine-regulated transcript (CART) in the treatment of depression. Med Hypotheses 69: 132-135.

Paxinos G, Watson C (1998). The Rat Brain in Stereotaxic Coordinates. Academic Press: London.

Porsolt RD, Anton G, Blavet N, Jalfre M (1978). Behavioural despair in rats: a new model sensitive to antidepressant treatments. Eur J Pharmacol 47: 379-391.

Redmond AM, Kelly JP, Leonard BE (1999). The determination of the optimal dose of milnacipran in the olfactory bulbectomized rat model of depression. Pharmacol Biochem Behav 62: 619-623.

Ruedi-Bettschen D, Feldon J, Pryce CR (2004). The impaired coping induced by early deprivation is reversed by chronic fluoxetine treatment in adult Fischer rats. Behav Pharmacol 15: 413-421.

Sarkar S, Wittmann G, Fekete C, Lechan RM (2004). Central administration of cocaine- and amphetamine-regulated transcript increases phosphorylation of cAMP response element binding protein in corticotropin-releasing hormone-producing neurons but not in prothyrotropin-releasing hormone-producing neurons in the hypothalamic paraventricular nucleus. Brain Res 999: 181-192.

Sergeyev V, Fetissov S, Mathé AA, Jimenez PA, Bartfai T, Mortas P et al (2005). Neuropeptide expression in rats exposed to chronic mild stresses. Psychopharmacology 178: 115-124.

Shabanov PD, Roik RO (2005). Evaluation of antidepressant activity in a model of depression-like state due to social isolation in rats. Eksp Klin Farmakol 68: 11-15.

Smith SM, Vaughan JM, Donaldson CJ, Rivier J, Li C, Chen A et al (2004). Cocaine- and amphetamine-regulated transcript activates the hypothalamic pituitary-adrenal axis through a corticotropinreleasing factor receptor-dependent mechanism. Endocrinology 145: 5202-5209.

Song C, Earley B, Leonard BE (1996). The effects of central administration of neuropeptide $\mathrm{Y}$ on behavior, neurotransmitter, and immune functions in the olfactory bulbectomized rat model of depression. Brain Behav Immun 10: 1-16.

Song C, Leonard BE (1995). Interleukin-2-induced changes in behavioural, neurotransmitter, and immunological parameters in the olfactory bulbectomized rat. Neuroimmunomodulation 2: 263-273.

Song C, Leonard BE (2005). The olfactory bulbectomised rat as a model of depression. Neurosci Biobehav Rev 29: 627-647.

Stanek LM (2006). Cocaine- and amphetamine-related transcript (CART) and anxiety. Peptides 27: 2005-2011. 
Stone EA, Quartermain D, Lin Y, Lehmann ML (2007). Central a1adrenergic system in behavioral activity and depression. Biochem Pharmacol 73: 1063-1075.

Tanaka M, Telegdy G (2008). Antidepressant-like effects of the CRF family peptides, urocortin 1, urocortin 2 and urocortin 3 in a modified forced swimming test in mice. Brain Res Bull 75: 509-512.

Thim L, Nielsen PF, Judge ME, Andersen AS, Diers I, Egel-Mitani M et al (1998). Purification and characterization of a new hypothalamic satiety peptide, cocaine and amphetamine regulated transcript (CART), produced in yeast. FEBS Lett 428: 263-268.

Vaarmann A, Kask A (2001). Cocaine- and amphetamine-regulated transcript peptide (CART(62-76))-induced changes in regional monoamine levels in rat brain. Neuropeptides 35: 292-296.
Vicentic A, Dominguez G, Hunter RG, Philpot K, Wilson M, Kuhar MJ (2004). Cocaine- and amphetamine-regulated transcript peptide levels in blood exhibit a diurnal rhythm: regulation by glucocorticoids. Endocrinology 145 4119-4124.

Vrang N (2006). Anatomy of hypothalamic CART neurons. Peptides 27: 1970-1980.

Wu B, Hu S, Yang M, Pan H, Zhu S (2006). CART peptide promotes the survival of hippocampal neurons by upregulating brain derived neurotrophic factor. Biochem Biophys Res Commun 347: 656-661.

Yang SC, Pan JT, Li HY (2004). CART peptide increases the mesolimbic dopaminergic neuronal activity: a microdialysis study. Eur J Pharmacol 494: 179-182.

Supplementary Information accompanies the paper on the Neuropsychopharmacology website (http://www.nature.com/npp) 